\title{
3D Image Side Sharpening Using Fourier Phase Only Synthetis Method
}

\author{
Amran Sitohang ${ }^{1}$, Petti Indrayati ${ }^{2}$ \\ 1,2 Manajemen Informatika, STMIK Pelita Nusantara \\ Email: amransitohang16@gmail.com, pettiindrayati12@gmail.com
}

\begin{tabular}{ll}
\hline Keywords & $\begin{array}{l}\text { Abstract. In the process of the Fourier Phase Only Synthetis method on two images, the } \\
\text { observer must get the impression that the imagery actually changes shape to an } \\
\text { intermediate form before it changes to the destination image. These changes must occur } \\
\text { in a regular and consistent manner to achieve the image of the goal. This sharpening } \\
\text { system is one of the systems that aims for this form change process is widely used in } \\
\text { applications in the field of entertainment, computer animation, scientific visualization } \\
\text { and education. The sharpening system on the 3-dimensional side of the image aims to } \\
\text { Fide Sharpening } \\
\text { Fourier Phase Only Synthetify the pattern of the image. Good image quality if it has good contrast and can } \\
\text { describe clear ridges and valleys structures. Based on previous research that the study } \\
\text { was conducted improvements with Fourier Phase Only Synthetis where the algorithm } \\
\text { used simultaneously estimates all the intrinsic properties of. The quality of image } \\
\text { sharpening relates to the clarity of ridge structure on the image side. A good image will } \\
\text { have a good contrast and will well depict ridges and valleys, if the fingerprint imagery } \\
\text { is of poor quality then it will have less contrast so it will less clearly describe the } \\
\text { boundaries of ridges (hills). From the implementation of Fourier Phase Only Synthetis } \\
\text { Analysis, using the main parameters ridge orientation image, has been successfully } \\
\text { obtained the results of image side improvement well. This image side improvement will } \\
\text { greatly help to improve the quality of 3-dimensional image extraction, by specifying } \\
\text { constant values to get the bestresults. }\end{array}$ \\
\end{tabular}

\section{INTRODUCTION}

With the development of image processing (Image processing) 3 dimensions, humans are vying to produce an attractive image of simple images that exist. In addition, in accordance with the development of time, image processing (Image Processing) 3 dimensions are increasingly becoming a necessity by many people, especially in the field of art, filmmaking as a special effectt on 3D imagery. One of the image processing that is currently popular and widely used in the world of film or art is image. The process of morphing method (field morphing), is the process to create an effect or increase grey level, where an object will be changed slowly into a destination object. Basically 3D image conversion using Synthetis Fourier Phase Only Method is done by creating frame images between the original image and the destination image and producing a better movie or image [1], [2].

Understanding crossPremiere, you use one of the transitions, Cross Dissolve, for both Fade In/Out and Dissolve. This means that if you place a transition between two video clips, the result will dissolve. And if you put a transition between a video clip and an empty space(which is interpreted as black by Premiere), the result will be Fade In or Fade Out. In other words, you dissolve your clip into black which is the definition of Fade Out or black soluble for the clip (ifyou placethe transition at the beginning of the video clip), which is the definition of Fade In. Click Dissolve folder in the Effects window to open it [3], [4].

Therefore, improving the quality of the image side should be the main priority before identifying parameters that are feature of objects in the image, for the next parameter is used in interpreting the image. One method that can perform the process of improving the quality of 3-dimensional imagery is the Fourier Phase Only Synthetismethod. The use of Fourier Phase Only Synthetis is based on the nature of sharpening the side of the image 3 dmensi fickle (non-stationary) means that the characteristics have different values on one part with the other in a fingerprint image [5], [6]. The quality of image sharpening relates to the clarity of ridge structure on the image side. Good imagery will have a good contrast and will well describe ridges and valleys, if the fingerprint image has less good quality then it will have less contrast so it will less clearly describe theboundaries of ridges (hills) With the development of shape change software on digital imagery, then it can be studied the animation process that occurs on an object [7]-[9]. The reason for using the Fourier Phase Only Synthetis method in this Jurnal Info Sains : Informatikan dan Sains is licensed under a Creative Commons Attribution-Non Commercial 4.0 International License (CC BY-NC 4.0) 
study is because Fourier Phase Only Synthetis is one of the algorithms that can calculate quickly. With the development of shape change software on digital imagery, it can be learned the animation process that occurs in an object. For example how to morph from a circular object into a rectangular object related to Grey Level Transformation [10], [11].

\section{METHODS}

The Software Engineering Body of Knowledge (SWEBOK) divides software engineering into 10 areas of knowledge, namely:

1. Software needs,

2. Software design

3. Construction software,

4. Software testing,

5. Software maintenance,

6. Configuration management software,

7. Software management,

8. Software processes,

9. Software methods and tools, and

10. Software quality.

'The factors that affect the planning, management, and selection of SQM activities and techniques are as follows:

1. System area to be occupied software (safety-critical, mission-critical, and business critical),

2. System and software needs,

3. Commercial (external) or standard (internal) components for use in systems,

4. Specific software engineering standards that can be applied,

5. Software methods and tools used for development and maintenance, and for quality improvement and evaluation,

6. Budget, staff, project organization, plans, and scheduling of all processes,

7. Expected user and system usage, and

8. Level of system integrity.

\subsection{Image}

An image is a 2-dimensional intensity function $\mathrm{f}(\mathrm{x}, \mathrm{y}, \mathrm{z})$, where $\mathrm{x}$ and $\mathrm{y}$ are spatial coordinates and $\mathrm{z}$ at a point $(\mathrm{x}, \mathrm{y})$ is the brightness of an image at a point. An image is obtained from the capture of the force of the light reflected by the object. An image in a coordinate system with its needs is accompanied by a coloring model that embellishes the image, accompanied by a sequence of ciphers that reveal its identity, equipped by a series that realizes the smoothness of the image, and placed specifically to keep it in existence. All the embodiment of this image is based on the embodiment of the pixel that is the element of its development, which in this case is expressed in size, color, pairing, and file.

According to Sutoyoso, Image is a two-dimensional image produced from a continuous twodimensional analog image into a discrete image through the samplingprocess. Digital imagery can be defined as a function of two variables, $f(x, y)$, where $x$ and $y$ are spatial coordinates while the value $\mathrm{f}(\mathrm{x}, \mathrm{y})$ is the intensity of the image at those coordinates. The basic technology for creating and displaying colors in digital imagery is based on research that a color is a combination of three basic colors, namely red, green, and blue(Red, Green, Blue - RGB). Each component is 8 bits long, so there are 256 grayish values for blue. The value of each pixel does not directly represent the degree of grayness, but the pixel value represents the index of the RGB table that makes the value of red grayness $(\mathrm{R})$, the green gray value $(\mathrm{G})$, and the blue gray value (B) for the corresponding pixel. In a black-andwhite image, the value $\mathrm{R}=\mathrm{G}=\mathrm{B}$ states that the black-and-white image has only one color channel. Black - white image is generally an 8-bit image. Richer color imagery is a 24-bit image Every pixel is 24 bits long, as each pixel instantly declares the red color component, the green component, and the blue component. Each component is 8 bits long. A 24-bit image is also called a 16 million-color image, 
as it is capable of producing $224=16,777,216$ color combinations. Images in BMP format there are three kinds: binary imagery, color imagery, and black-and-white imagery (grayscale). Binary images have only two gray values, 0 and 1 .

\section{RESULT AND DISCUSSION}

\subsection{Image Data Management Process}

Images represented in the form of matrices have large dimensions with rows and columns indicating a point in the image and the suitability of the value of the matrix element identifies the level at that point. 3D Image Change is based on color recognition by using one of the classic operators namely mask. laplace The data used in this study are some facial imagery for testing, where the image used is a grayscale image with an image size of $256 \times 256$ pixels, then the image will undergo a process to obtain similarities that are the image results (Output Image). The flow process diagram of image data processing that will be used in this study is shown in figure 1 .

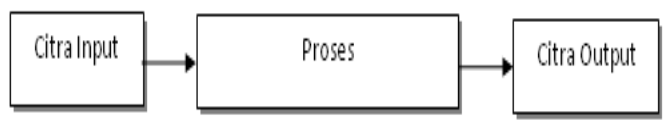

Figure 1 Flow Process Of Fourier Image Processing

Input image (input) is an image that has a color intensity ranging from 0 as a minimum value to 255 which is the maximum value. Input images that have a size of $5 \times 5$ pixels are then converted into a matrix form of $5 \times 5=25$, for each image. To get the value of grey level is the result of summing the $\mathrm{R}+\mathrm{G}+\mathrm{B}$ value of each pixel divided by 3 . The formula used is:

$$
\text { Greylevel }=\frac{R+G+B}{3}
$$

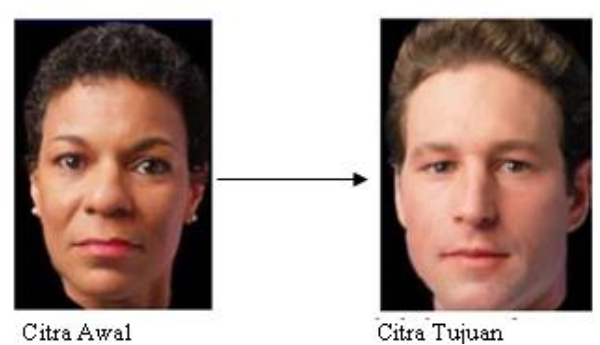

Figure2. Image size 5 x 5 pixels

Here is the RGB value of each image pixel in figure 3 above:

Table 1. RGB Values

\begin{tabular}{cccc}
\hline Pixel & R & G & B \\
\hline 0 & 222 & 220 & 204 \\
1 & 220 & 220 & 212 \\
2 & 237 & 207 & 192 \\
3 & 220 & 220 & 212 \\
4 & 220 & 228 & 220 \\
5 & 220 & 220 & 212 \\
6 & 220 & 228 & 220 \\
7 & 228 & 228 & 218 \\
8 & 220 & 228 & 220 \\
9 & 228 & 230 & 228 \\
10 & 212 & 220 & 212 \\
11 & 220 & 220 & 212 \\
12 & 220 & 220 & 212 \\
13 & 212 & 212 & 196 \\
14 & 220 & 220 & 212
\end{tabular}

Jurnal Info Sains : Informatikan dan Sains is licensed under a Creative Commons Attribution-Non Commercial 4.0 International License (CC BY-NC 4.0) 


\begin{tabular}{llll}
15 & 204 & 204 & 188 \\
16 & 152 & 157 & 152 \\
17 & 190 & 187 & 190 \\
18 & 179 & 181 & 168 \\
19 & 187 & 202 & 197 \\
20 & 187 & 202 & 197 \\
21 & 204 & 204 & 188 \\
22 & 212 & 220 & 212 \\
23 & 212 & 212 & 204 \\
\hline
\end{tabular}

Based on the RGB value in the table above, it is calculated the greylevel color value, then obtained the following result:

Table 2 Greyleve value

\begin{tabular}{|c|c|c|c|c|}
\hline Pixel & $\mathrm{R}$ & $\mathrm{G}$ & $\mathrm{B}$ & Greylevel \\
\hline 0 & 222 & 220 & 204 & 215 \\
\hline 1 & 220 & 220 & 212 & 217 \\
\hline 2 & 237 & 207 & 192 & 212 \\
\hline 3 & 220 & 220 & 212 & 217 \\
\hline 4 & 220 & 228 & 220 & 223 \\
\hline 5 & 220 & 220 & 212 & 217 \\
\hline 6 & 220 & 228 & 220 & 220 \\
\hline 7 & 228 & 228 & 218 & 225 \\
\hline 8 & 220 & 228 & 220 & 223 \\
\hline 9 & 228 & 230 & 228 & 229 \\
\hline 10 & 212 & 220 & 212 & 215 \\
\hline 11 & 220 & 220 & 212 & 217 \\
\hline 12 & 220 & 220 & 212 & 217 \\
\hline 13 & 212 & 212 & 196 & 207 \\
\hline 14 & 220 & 220 & 212 & 217 \\
\hline 15 & 204 & 204 & 188 & 199 \\
\hline 16 & 152 & 157 & 152 & 154 \\
\hline 17 & 190 & 187 & 190 & 189 \\
\hline 18 & 179 & 181 & 168 & 176 \\
\hline 19 & 187 & 202 & 197 & 195 \\
\hline 20 & 187 & 202 & 197 & 195 \\
\hline 21 & 204 & 204 & 188 & 199 \\
\hline 22 & 212 & 220 & 212 & 215 \\
\hline 23 & 212 & 212 & 204 & 209 \\
\hline 24 & 221 & 212 & 212 & 215 \\
\hline
\end{tabular}

Jurnal Info Sains : Informatikan dan Sains is licensed under a Creative Commons Attribution-Non Commercial 4.0 International License (CC BY-NC 4.0) 
The greylevel values in Table 2 are converted into matrix forms as follows:

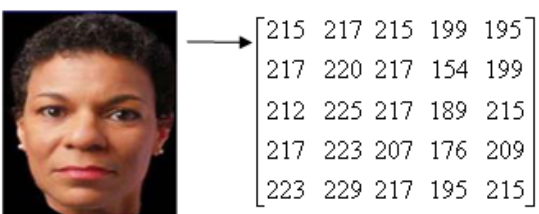

Figure 3. Input Image Matrix

The process of rebranding 3D imagery is a processing of images to find the grayscale level limits of pixels in an image. many approaches are taken to the problem. In this study, an approach was taken to detection problems with AdaGreyLevel Tranformation.

\subsection{Discussion}

In accordance with the results of the research obtained the creation of image processing or animation that is still manually. Based on this, an image fourier application was built to help create an animation / 3D image. So in this 3D Image Change, using the Fourier Method (FieldFourier). This method is a method of converting the initial image into a destination image, the object is the input image and the resulting image,the goal is toAdatransform the 3D image orimage object in the database using the RGB color of theface object. System analysis is an activity to learn the interaction of the system consisting of process actors in the system of procedures and data and what is needed in the creation of this application. The purpose of system analysis is to get an analysis result that corresponds to the level of user and system needs both in terms of input needed and desired system output. And this system is designed using the basic visual programming language 6.0.The results of this analysis will later become inputs for the design process. Output image is an image that has a color intensity ranging between 0 and 1 (binary image) which is the result of convolution of the process of changing 3D Imagery. And output image that has a maximum image size of 256x256 pixels with input image that has the same sizeand format is also only done for images of the same type thatis bitmap image (*.bmp, *jpeg) to bitmap image (*.bmp, *jpeg). To get a better image.

\section{CONCLUSION}

The design of applications capable of sharpening and changing 3-dimensional objectshas been completed by the decision that the system designed in the application In the process of sharpening the image and become the purpose for the use of side objects processed using the Method Fourier Phase Only Synthetis. This application can converthasilkan sebuah sistm atau change yang change objects like bitmap image (*.bmp) to bitmap image (*.bmp,) with determination sebuah image diproses lagi kedalam sebuah citra gambardengan metode Fourier Phase Only Synthetis, sehingga tingkatsharpening process on the side of the picture tersebut menjadi lebih baik.

\section{REFERENCE}

[1] P. Li and H. Xiao, "An Improved Filtering Method for Quantum Color Image in Frequency Domain," Int. J. Theor. Phys., vol. 57, no. 1, 2018, doi: 10.1007/s10773-017-3561-x.

[2] C. J. Russo and R. Henderson, "Ewald sphere correction using a single side-band image processing algorithm," Ultramicroscopy, vol. 187, 2018, doi: 10.1016/j.ultramic.2017.11.001.

[3] S. R. Fadilah, M. D. M. Manessa, and R. R. Atmawidjaja, "EKSTRAKSI DATA KEDALAMAN MENGGUNAKAN DATA CITRA LANDSAT-8," J. ONLINE Mhs. Bid. Tek. Geod., vol. 1, 2018.

[4] E. Junianto and M. Z. Zuhdi, "Penerapan Metode Palette untuk Menentukan Warna Dominan dari Sebuah Gambar Berbasis Android," J. Inform., vol. 5, no. 1, 2018, doi: 10.31311/ji.v5i1.2740.

[5] A. Gandhamal, S. Talbar, S. Gajre, A. F. M. Hani, and D. Kumar, "Local gray level S-curve transformation - A generalized contrast enhancement technique for medical images," Comput. Biol. Med., vol. 83, 2017, doi: 10.1016/j.compbiomed.2017.03.001.

[6] H. Di and D. Gao, "Gray-level transformation and Canny edge detection for 3D seismic

Jurnal Info Sains : Informatikan dan Sains is licensed under a Creative Commons Attribution-Non Commercial 4.0 International License (CC BY-NC 4.0) 
discontinuity enhancement," Comput. Geosci., vol. 72, 2014, doi: 10.1016/j.cageo.2014.07.011.

[7] J. J. De Santiago-Perez, J. R. Rivera-Guillen, J. P. Amezquita-Sanchez, M. Valtierra-Rodriguez, R. J. Romero-Troncoso, and A. Dominguez-Gonzalez, "Fourier transform and image processing for automatic detection of broken rotor bars in induction motors," Meas. Sci. Technol., vol. 29, no. 9, 2018, doi: 10.1088/1361-6501/aad3aa.

[8] N. Collings, Fourier Optics in Image Processing. 2018.

[9] S. A. Broughton and K. Bryan, Discrete fourier analysis and wavelets: Applications to signal and image processing: Second edition. 2018.

[10] S. Hu et al., "Weakly supervised deep learning for covid-19 infection detection and classification from ct images," IEEE Access, vol. 8, pp. 118869-118883, 2020.

[11] D. Pandurangan, R. S. Kumar, L. Gebremariam, L. Arulmurugan, and S. Tamilselvan, "Combined Gray Level Transformation Technique for Low Light Color Image Enhancement," J. Comput. Theor. Nanosci., vol. 18, no. 4, 2021, doi: 10.1166/jctn.2021.9392. 